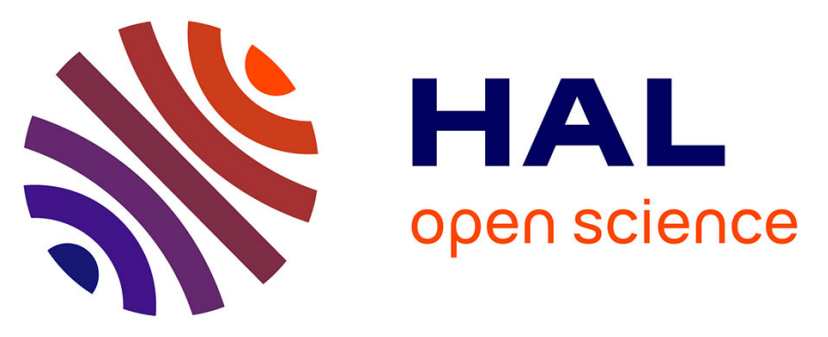

\title{
Optical near-field enhancement around lithographic metallic nanostructures using an azo-dye polymer: direct observation and realization of sub-wavelength complex structures
}

Christophe Hubert, Serguei Kochtcheev, Gilles Lerondel, Alexandre Vial, Renaud Bachelot, Pascal Royer, Anna Rumyantseva, Johan Grand, Laurent Billot, Gilbert Chang, et al.

\section{- To cite this version:}

Christophe Hubert, Serguei Kochtcheev, Gilles Lerondel, Alexandre Vial, Renaud Bachelot, et al.. Optical near-field enhancement around lithographic metallic nanostructures using an azo-dye polymer: direct observation and realization of sub-wavelength complex structures. MRS Fall meeting, Nov 2004, Boston, United States. 10.1557/PROC-838-O5.2 . hal-02463107

\section{HAL Id: hal-02463107 https://hal-utt.archives-ouvertes.fr/hal-02463107}

Submitted on 28 Sep 2021

HAL is a multi-disciplinary open access archive for the deposit and dissemination of scientific research documents, whether they are published or not. The documents may come from teaching and research institutions in France or abroad, or from public or private research centers.
L'archive ouverte pluridisciplinaire HAL, est destinée au dépôt et à la diffusion de documents scientifiques de niveau recherche, publiés ou non, émanant des établissements d'enseignement et de recherche français ou étrangers, des laboratoires publics ou privés.

\section{(ㄷ)(i)}

Distributed under a Creative Commons Attribution| 4.0 International License 


\title{
Optical near-field enhancement around lithographic metallic nanostructures using an azo- dye polymer: direct observation and realization of sub-wavelength complex structures
}

\author{
Christophe Hubert ${ }^{1}$, Anna Rumyantseva ${ }^{1}$, Gilles Lérondel ${ }^{1}$, Johan Grand ${ }^{1}$, Sergeï Kostcheev ${ }^{1}$, \\ Laurent Billot ${ }^{1}$, Alexandre Vial ${ }^{1}$, Renaud Bachelot ${ }^{1}$, and Pascal Royer ${ }^{1}$ \\ Gilbert Chang ${ }^{2,3}$, Stephen K. Gray ${ }^{2}$, and Gary P. Wiederrecht ${ }^{2}$, \\ George C. Schatz ${ }^{3}$ \\ ${ }^{1}$ Laboratoire de nanotechnologie et d'Instrumentation Optique, Université de Technologie de \\ Troyes, 12 rue marie curie, B.P. 2060, 10000 Troyes, France \\ ${ }^{2}$ Chemistry Division and Center for Nanoscale Materials, Argonne National Laboratory, \\ Argonne, IL 60439 \\ ${ }^{3}$ Department of Chemistry and Institute for Nanotechnology, Northwestern University, Evanston \\ IL 60208
}

\begin{abstract}
We report on the direct observation of optical near-field enhancement around metallic nanoparticles. We used an easy to set up approach which consists in irradiating a photosensitive azo-dye polymer film spin-coated on metallic nanostructures. Photoinduced topographical modifications of the polymer film surface are characterized after irradiation by atomic force microscopy (AFM). Comparisons between AFM images and numerical simulations show that these photo-induced topography agrees with the near-field intensity distribution around the nanostructures. The possibility of generating complex structures is demonstrated.
\end{abstract}

\section{INTRODUCTION}

Near-field optics has attracted much attention during the past two decades because it overcomes the diffraction limit of conventional microscopes. At present, most widely used methods for optical near-field imaging of nanostructures are photon scanning tunneling microscopy (PSTM), aperture scanning near-field optical microscopy (SNOM) and apertureless scanning near field optical microscopy (ASNOM) ${ }^{1-3}$. The main difficulties related to these techniques are signal discrimination as well as image interpretation. Indeed, images can be affected by artifacts and, the interaction between the probe and the structures studied can lead to perturbations in the nearfield distribution. In order to avoid these problems, other alternative techniques have recently been proposed, using a photosensitive polymer to map the optical near field of different kinds of particles. ${ }^{4-6}$ While the different results obtained have successfully shown topographic features induced by the particles, they have not been able to spatially resolve the optical fields with the precision of scanning probe methods.

We report in this work an original approach based on the exposure of lithographically designed metallic nanostructures coated with a photosensitive azo-dye polymer. The dipolar response of excited metal nanoparticles is clearly observed. Experimental results are compared with numerical simulations performed with the FDTD method. The effect of light polarization direction as well as the generation of sub-micrometer complex structures are emphasized. 


\section{EXPERIMENTAL METHOD}

Sample preparation process can be divided into three steps, as illustrated in figure 1 .

3) Argon laser $\left.\lambda=514 \mathrm{~nm} \quad \begin{array}{c}\text { Linear } \\ \text { Circular }\end{array}\right\}$ Polarization

2)

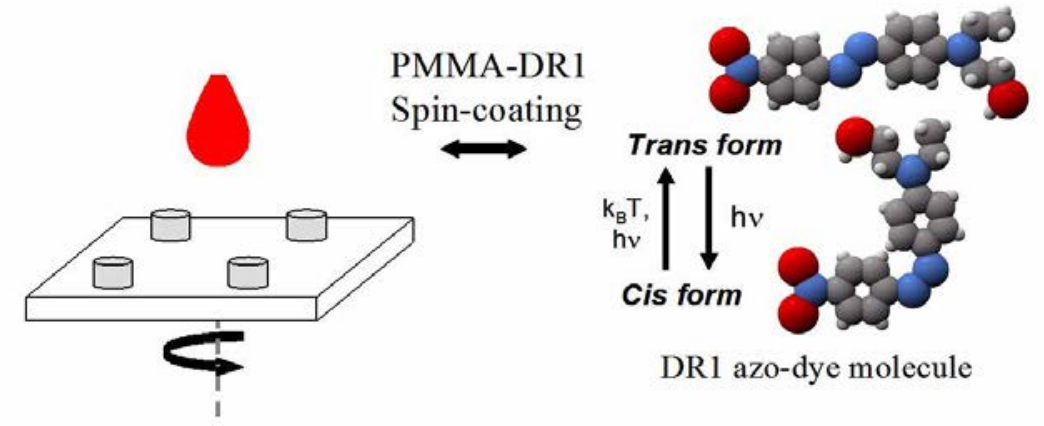

1)

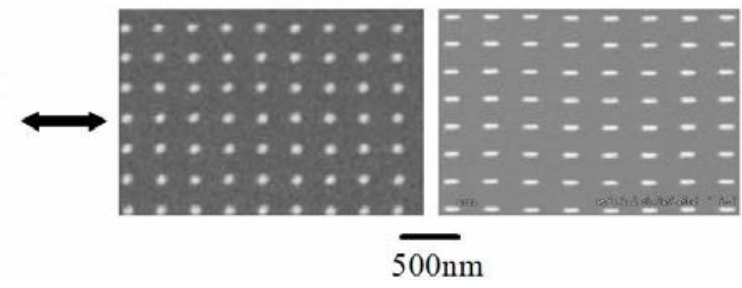

Figure 1. Schematic view of the approach: (1) Fabrication of metallic nanostructures on glass. Exemples of arrays of dots and ellipsoids are shown on the two electron microscopy (SEM) images. (2) Spin-coating of the PMMA-DR1 azo-polymer on the metallic structures. The trans and cis isomeric forms of the Dispersed Red 1 azo-dye molecule are also shown. (3) Irradiation of the sample with the 514nm line of an Argon ion laser. Circular or linear polarization of the incident laser beam can be used.

The first step is the fabrication of metallic nanostructures using the following electron-beam lithography procedure. A $150 \mathrm{~nm}$ 950k PMMA layer is spin-coated on glass substrates. Samples are then pre baked at $160^{\circ} \mathrm{C}$ for a few hours. In order to prevent substrate charging, a thin Aluminum layer is deposited on the PMMA surface. Exposure is performed using a scanning electron microscope Hitachi S-3500N. Following the exposure, the patterns are developed using a solution of methylisobutylketone (MIBK) : isopropyl alcohol (IPA) 1:3 and the desired thickness $(60 \mathrm{~nm})$ of silver or gold is evaporated on the sample. Lift-off procedure is finally performed using acetone. Homogeneity of the samples is checked by means of a Scanning Electron Microscope operating in low vacuum mode. The second step of the process consists of spin coating the copolymer on the metallic nanostructures. The copolymer is composed of the Disperse Red One (DR1) (4-(N-(2-hydroxyethyl)-n-ethyl)-amino-4'-nitroazobenzene) azodye molecule grafted as side chain onto poly(methyl methacrylate) (PMMA) in a 30/70 molar ratio (here after referred to as PMMA-DR1). The maximum absorption wavelength of a PMMA-DR1 azopolymer film is $470 \mathrm{~nm}$ and is due to the DR1 azodye molecule absorption (PMMA is transparent in the visible range). Spin-coating is performed from a solution composed of the 
copolymer diluted in 1,1,2-trichloroethane, followed by one hour drying at $80^{\circ} \mathrm{C}$ to fully evaporate the solvent. Polymer films with different thicknesses can be obtained by varying either the spin-coater rotation speed or the PMMA-DR1 concentration. The last step of this method is the irradiation of the sample. We used two kinds of illumination, the 514nm line of an Argon-ion laser or a frequency doubled, diode-pumped Nd:YAG laser, (532nm). Whatever the illumination source, a polarizer was also used to ensure a linear polarization. Light state polarization was varied from linear to circular using a quarter wave plate after the first polarizer. The sample is then set perpendicular to the incident beam whose wavelength was chosen to be in the absorption band of the DR1 azodye molecule. Imaging of the photoinduced topographic modifications at the polymer film surface after irradiation is performed with an AFM (Explorer-Veeco).

This approach has numerous advantages over other nano-optical characterization methods. The first one is that topographic modifications at the polymer film surface are directly imaged after irradiation and without any chemical treatment, with an atomic force microscope (AFM). The second one is that it is possible with the polymer solvent to remove the polymer film after irradiation of the sample. It is thus possible to use the same sample several times, without any degradation of the lithographic structures. Finally, the last advantage is that, in addition to avoiding sample-probe interactions, this technique overcomes the problems of low signal to noise ratios that can occur in SNOM measurements.

\section{RESULTS AND DISCUSSION}

Due to their remarkable photoisomerization properties, azo-dye molecules have been the subject of many studies. Following excitation with a polarized laser light and cis-trans isomerization, it is now well established that thermal diffusion enables a molecular rotation within the azopolymer matrix leading finally to a full reorientation of the dye molecules. ${ }^{8}$ In addition to this reorientation, a mass transport phenomenon was observed from high to low intensity regions. This may originate from a coupling effect between translation and rotation movements.

Recently, it was shown that irradiation of an azo-dye polymer film with an interference pattern of coherent light could induce a topographic modification and lead to the formation of a Surface Relief Grating (SRG). ${ }^{10-11}$ It has been established that the phase relationship between the interference pattern and the resulting SRG is such that the light intensity maxima of the fringes coincide with the surface profile minima. Since the first observations, it is recognized by the different authors that the mechanism at the origin of SRG formation is directly connected with the photoisomerization properties of azobenzene derivatives and all models proposed so far agree on the existence of a photoinduced mass transport occurring well below the glass transition temperature. $^{12-14}$

In this paper, experimental observations are compared to theoretical modeling. Near-field optical intensities are calculated using the Finite-Difference Time-Domain (FDTD) method ${ }^{15}$. The negative image of the computed near-field intensities can be correlated with the observed photoinduced topographic modifications. The negative image illustrates the fact that a mass transport occurs from high intensity regions to low intensity regions. Our proposed model based on the negative intensity actually corresponds to the first order approximation of the comprehensive photo-assisted matter migration model given by Ref. 12 .

The FDTD calculations were fully three-dimensional with appropriate periodic and absorbing boundary conditions. ${ }^{16}$ The metals were described by Drude models with parameters fit to the experimental dielectric constant data for the wavelengths of interest, as described in Ref. 16. The 
glass substrate and PMMA-DR1 were also included in the calculations, with dielectric constants of 2.25 and 2.89, respectively. Fourier transformations of the time-domain fields on the wavelengths of interest then yield steady-state fields and thus field intensities.

Figure 2 shows the results obtained with an array of silver nanoparticles. The irradiation wavelength used lies in the particles' plasmon resonance position. This is confirmed by an FDTD calculation of the extinction spectrum which shows a maximum near 540nm.

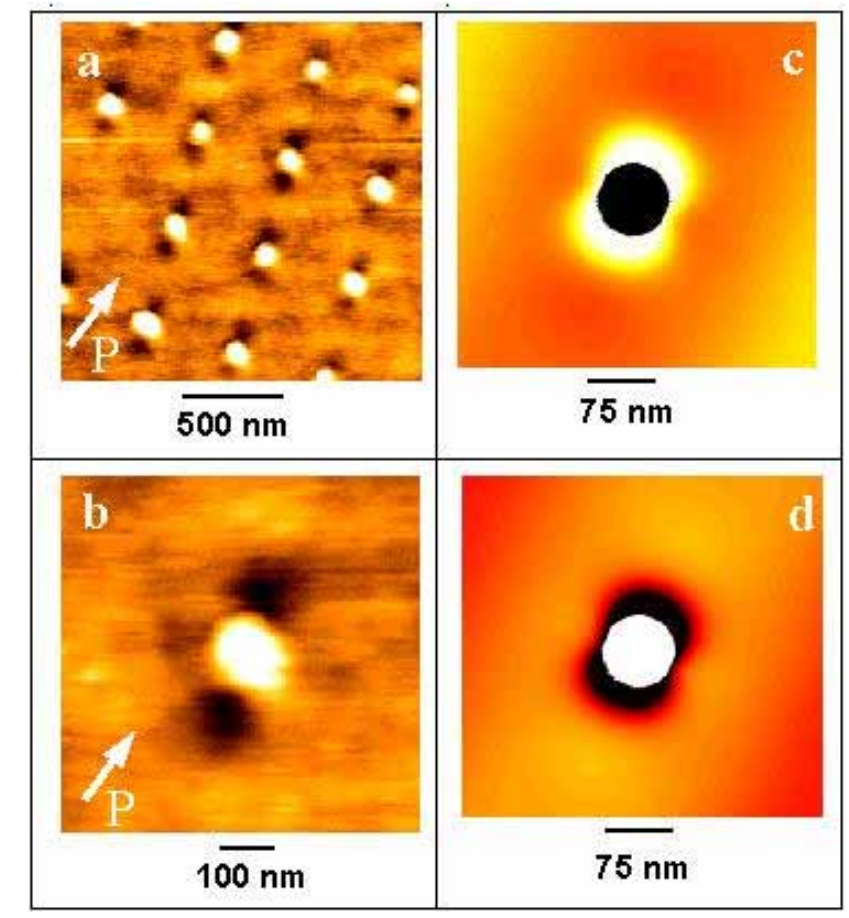

Figure 2. Topographic images and theoretical calculations of optical near-fields around silver nanoparticles. AFM image recorded after irradiation of silver particles covered with PMMADR1 $(a, b)$. Irradiation wavelength, time, and intensity were, respectively, 532nm, 20 minutes and $50 \mathrm{~mW} / \mathrm{cm}^{2}$. White arrows in the images indicate the polarization direction. The silver particles have a diameter of $75 \mathrm{~nm}$, a height of $50 \mathrm{~nm}$, and a periodicity of $500 \mathrm{~nm}$. (c) Image of the theoretically computed near-field intensity around a particle indicated in black, and its negative image (d). The color scale in (a)-(d) is such that white is high and black is low.

After irradiation, two holes can be observed (figures. 2a-b) at the polymer film surface, close to the particles and oriented along the incident light polarization. The depth of each hole is $\approx 4 \mathrm{~nm}$, with diameter $\approx 100 \mathrm{~nm}$, which corresponds approximately to $\lambda / 5$ without taking into account the tip convolution. The depressions correlate remarkably well with the expected dipolar near-field spatial profile, which to our knowledge has not been resolved with any other method using photosensitive polymers. ${ }^{4-6}$ Figure $2 \mathrm{c}$ displays the theoretical electric field intensity and figure $2 \mathrm{~d}$ displays its negative image, which agrees qualitatively with its experimental counterpart, figure $2 \mathrm{~b}$. Indeed, numerical calculations show that intensity maxima are located at the same position as the holes observed in the topographic image. The positions of the dumps are consistent with molecular transport from high intensity regions to low intensity regions and the topographic modifications observed after irradiation are thus due to a mass transport phenomenon photo- 
induced by the optical near-field of the metallic silver particles, produced by the plasmon resonance. It can be observed that there is not a perfect matching of negative field intensity to surface topography: on the theoretical image, the field intensity is more localized near the particle edges, which could be due to tip convolution as well as to molecular diffusion.

We have next studied the influence of the light polarization direction and figure 3 shows the result obtained with silver nanoparticles covered with PMMA-DR1 but now irradiated with a circularly polarized laser beam.

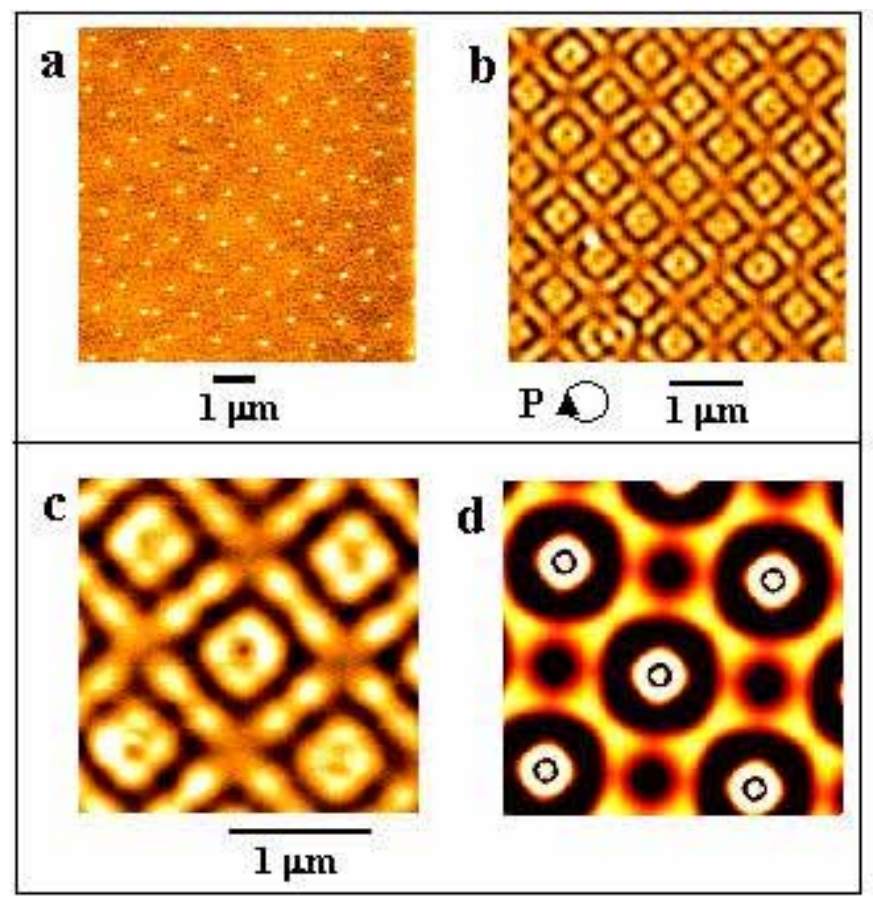

Figure 3. Topographic images and theoretical calculations of silver nanoparticles illuminated with circularly polarized laser light. AFM images recorded before (a) and after (b) irradiation of silver particles covered with PMMA-DR1. (c) is a blow-up of (b). Irradiation wavelength, time and intensity are $514 \mathrm{~nm}, 30$ minutes and $100 \mathrm{~mW} / \mathrm{cm}^{2}$, respectively. No drying was performed after spin-coating and 1-1-2- trichloroethane was used as a solvent. Silver particles are 50nm in height, $100 \mathrm{~nm}$ in diameter and the spacing is equal to $1 \mu \mathrm{m}$. (d) is the theoretical negative field image corresponding to (c). The color scale in (d) is such that white is high and black is low.

The silver particles are $50 \mathrm{~nm}$ in height, $100 \mathrm{~nm}$ in diameter and have a periodicity of $1 \mu \mathrm{m}$ (figure 3a). In this case, complex topographic modifications can be observed at the polymer film surface, as shown in figures $3 \mathrm{~b}$ and $3 \mathrm{c}$. The experimental observations can be compared with the computed negative of the electric field intensity shown in figure $3 \mathrm{~d}$. The AFM image of figure $3 \mathrm{c}$ shows that an inner array of lobes around each particle can be distinguished, as well as an outer array of lobes, whose periodicity is equal to the lattice spacing. These outer lobes probably result from far-field interferences of diffraction orders. Quite encouragingly, the negative computed field intensity of figure $3 \mathrm{~d}$ also shows inner and outer high relief features around the particles, although they are not as structured as the experimental ones (figure $3 \mathrm{c}$ ). This probably originates from the fact that the diffusion of azodye molecules is not actually taken into account in the 
theoretical calculations which thus cannot perfectly reproduce the behavior of the chromophores under illumination with very intense localized near-fields.

\section{CONCLUSIONS}

The different results presented here confirm that the proposed near-field photochemical imaging approach is a straightforward, robust alternative or complement to scanning probe methods for near-field imaging. Remarkably, the method enables the visualization of notable near-field phenomena, such as for example the dipolar responses from metallic nanoparticles following their excitation with a polarized laser light. This nano-optics approach can be extended to other photo-sensitive materials and more complex structures. Furthermore, this method may ultimately be applied to the nano-optical manipulation of molecular motors to produce material mass transport at a nanometer scale.

\section{ACKNOWLEDGMENTS}

The work at Argonne was supported by the U.S. Department of Energy, Office of Basic Energy Sciences, Division of Chemical Sciences, Geosciences, and Biosciences under DOE contract W-31-109-ENG-38. Work at Northwestern University was supported by DOE grant DEFG02-03ER15487.

\section{REFERENCES}

1. J. R. Krenn, M. Salerno, N. Félidj, B. Lamprecht, G. Schider, A.Leitner, F. R. Aussenegg, J. C. Weeber, A. Dereux, and J. P. Goudonnet, J. Microsc. 202, 122, (2000)

2. A. Bouhelier, T. Huser, H. Hamaru, H. J. Güntherodt, D. W. Pohl, F. I. Baida, and D. Van Labeke, Phys. Rev. B. 63, 155404, (2001).

3. R. Hillendrand, F. Keilmann, P. Hanarp, D. S. Sutherland, and J. Aizpurua, Appl. Phys. Lett., 83, 368, (2003).

4. P. Andre, F. Charra, P. A. Chollet, and M. P. Pileni, Adv. Mat. 14, 601, (2002).

5. T. Ikawa, M. Hasegawa, M. Tsuchimori, O. Watanabe, Y. Kawata, C. Egami, O. Sugihara, and N. Okamoto, Synt. Met. 124, 159, (2001).

6. P. G. Kik, S. A. Maier, and H. A. Atwater, Mat. Res. Soc. Symp. Proc 705, 101, (2002).

7. J. Grand, S. Kostcheev, J. L. Bijeon, M. Lamy de la Chapelle, P. M. Adam, A. Rumyantseva, G. Lérondel, and P. Royer, Synt. Met. 139, 621, (2003).

8. C. Jones, and S. Day, Nature 351, 15, (1991).

9. D. B. Hall, A. Dhinojwala, and M. Torkelson, Phys. Rev. Lett. 79, 103, (1997).

10. D. Y. Kim, S. K. Tripathy, L. Li, and J. Kumar, Appl. Phys. Lett. 66, 1166, (1995).

11. P. Rochon, E. Batalla, and A. Natansohn, Appl. Phys. Lett. 66, 136, (1995).

12. P. Lefin, C. Fiorini, and J. M. Nunzi, Opt. Materials 9, 323, (1998).

13. C. J. Barrett, P. Rochon, and A. Natansohn J. Chem. Phys., 109, 1505, (1998).

14. S. Bian, L. Li, J. Kumar, D. Y. Kim, J. Williams, and S. K. Tripathy, Appl. Phys. Lett. 73, 1, (1995).

15. A. Taflove, and S. C. Hagness, "Computational Electrodynamics: The Finite-Difference Time-Domain Method," (Artech House, Boston, $2^{\text {nd }}$ edition, 2000).

16. S. K. Gray, and T. Kupka, Phys. Rev. B. 68, 045415, (2003). 